\title{
Application of anthracnose resistance-associated molecular markers in the detection of resistant chili pepper cultivars in Vietnam
}

\author{
Vi An Ly, Thao Phuong Thi Truong, Thanh Hao Nguyen*
}

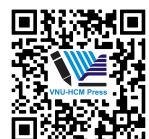

Use your smartphone to scan this QR code and download this article University of Science, Vietnam National
University, Ho Chi Minh City, Vietnam

\section{Correspondence}

Thanh Hao Nguyen, University of Science, Vietnam National University, Ho Chi Minh City, Vietnam

Email: nthao@hcmus.edu.vn

History

- Received: 2020-05-19

- Accepted: 2020-07-13

- Published: 2020-07-27

DOI : 10.32508/stdj.v23i3.2395

\section{Check for updates}

\section{Copyright}

(c) VNU-HCM Press. This is an openaccess article distributed under the terms of the Creative Commons Attribution 4.0 International license.

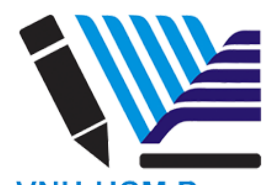

VNU-HCM Press

\begin{abstract}
Introduction: Colletotrichum species is responsible for anthracnose, a worldwide serious disease, causing an important loss in chili pepper production. Therefore, screening disease resistant and sensitive chili pepper cultivars in Vietnam is important not only for in-depth studies of disease resistance-associated molecular mechanisms but also for chili production improvement via molecular marker-assisted breeding in Vietnam. Methods: To this end, in this study, two Colletotrichum isolates were obtained from the infected fruits collected from chili pepper (Capsicum annuum) fields in Tra Vinh province. According to the morphology analysis and the sequencing results of the internal transcribed spacer (ITS) regions, these isolates were identified as C. scovillei and C. acutatum. In order to identify the anthracnose-resistant chili pepper cultivars, the pathogenicity test was conducted by infecting fully developed green fruits of eleven chili pepper cultivars with the two isolated Colletotrichum strains. Results: CN404 and HNCS were the two strongest anthracnoseresistant cultivars. Two chili pepper cultivars, TV3 and PN400, showed different resistance tendencies to each Colletotrichum isolates. Four different SSR molecular markers were used in this study to identify the potential molecular markers associated with anthracnose resistance traits in chili pepper cultivars. Among the four examined markers, HpmsE126 was detected in two anthracnoseresistant chili pepper cultivars, suggesting its close relation to the anthracnose resistance trait in chili pepper. Conclusion: Given that two of the three most anthracnose-resistant cultivars, CN404 and TV3, possess HpmsE126 marker, this marker can be used to detect anthracnose-resistant lines in chili pepper breeding in Vietnam.

Key words: Chili pepper, anthracnose, molecular marker
\end{abstract}

\section{INTRODUCTION}

In Vietnam, chili pepper is an important crop with high economic value. However, the annual chili yield is greatly affected by diseases caused by bacteria and fungi. One of the most well-known diseases in chili pepper is the anthracnose disease caused by the Colletotrichum fungi species. These fungi were known to infect not only chili pepper but also other crops and orchard plants, such as apple, mango, coffee, etc. ${ }^{1-4}$. Multiple Colletotrichum species have been found to be responsible for the anthracnose disease in chili pepper including C. capsici, C. acutatum, C. gloeosporioides, C. dematium, C. nigrum, C. atramentarium, C. coccodes and C. scovillei ${ }^{5,6}$. Apart from C. acutatum, C. capsici, C. gloeosporioides, recent studies in Vietnam have revealed a number of Colletotrichum species infecting chili pepper including, C. nigrum, C. siamense, C. fructicola and C. truncatum ${ }^{7,8}$.

Among five domesticated chili pepper species, including C. annuum, C. baccatum, C. chinense, C. frutescens and C. pubescens, C. annuum is the most commercially important species but is highly susceptible to anthracnose disease. The anthracnose resistance was introduced to $C$. annuum by crossing with other Capsicum species ${ }^{9,10}$. The conventional breeding and selection processes of diseaseresistant cultivars are often time-consuming and require financial resources for pathogenicity testing on large-scale. Different QTL mappings of anthracnose resistance were performed in the cross between C. annuum and other Capsicum species discovered potential markers linked to anthracnose resistance trait ${ }^{11,12}$. The identification of anthracnose resistance-associated molecular markers allowed the marker-assisted or based breeding, which is less timeconsuming and more cost-effective compared to conventional breeding ${ }^{13-15}$. Given that anthracnose is one of the most destructive fungal diseases in chiligrowing areas, including tropical Asian countries, e.g. Vietnam ${ }^{16}$, thus the isolation of new resistant cultivars via molecular marker-based breeding will help to improve chili production and further bring economic 
benefits from chili pepper cultivation.

Therefore, the objectives of this study were (i) identifying the Colletotrichum species majorly causing the anthracnose disease in chili pepper in Tra Vinh province (Vietnam), (ii) finding the cultivars showing resistance to these pathogens among commercial chili pepper cultivars in Vietnam, and most importantly, (iii) determining the potential anthracnose resistance-associated molecular markers which can be potentially applied further in chili pepper breeding in Vietnam.

\section{MATERIALS AND METHODS}

\section{Plant growth condition}

One wild bird-eye chili pepper line (TV3) found in Tra Vinh province and ten commercial cultivars (CN404, HNCS, CP01, HNN1, SGX5, SGX6, HN7777, TN535, HNNS, and PN400) were used in this study. Seeds from eleven cultivars were sown on small soil pots. At the 4-leaf stage, individual seedlings were transferred to pots with $18 \mathrm{~cm}$ in diameter. Plants were watered every morning with 21 of water. Nutrients were supplied to each plant every two weeks with $250 \mathrm{ml}$ of 1/10 MS (Murashige \& Skoog) mineral solution. Plants were kept in a net house to avoid insects. Plants that were infected by mealybug were isolated and treated with insecticide (Bihopper 207EC, Binh Dien - Mekong limited company) until recovered.

\section{Isolation of pathogenic fungi species}

Fruits showing anthracnose symptoms (e.g., rounded necrosis spots on the fruit) were collected from chili pepper fields in Tra Vinh province. Infected fruit samples were washed five times by shaking in sterile water and dried under a laminar airflow chamber prior to surface sterilization with $70 \%$ ethanol for 2 min. The $0.5 \mathrm{~cm} \times 0.5 \mathrm{~cm}$ fruit tissues containing the infected region were transferred to potato dextrose agar (PDA, $4 \%$ potato starch, $2 \%$ dextrose, $1.5 \%$ agar) plates kept at $25^{\circ} \mathrm{C}$ under $16 \mathrm{~h}$ light $/ 8 \mathrm{~h}$ dark condition in an incubation room for seven days. Purified fungal strains were obtained after three consecutive sub-cultures on PDA plates. The pure fungal cultures were maintained on PDA plates for Colletotrichum identification and pathogenicity test.

\section{Morphological analysis of isolated pathogenic fungi species}

Pure cultures isolated from infected fruits were first morphologically analyzed to identify the putative Colletotrichum strains. The morphology of the fungi strains was analyzed by observing fungal colonies grown on PDA plates, conidia form, and the appressoria formation. For appressoria preparation, a small piece of thin PDA medium was prepared on a sterile glass microscopy slide. A small spore fragment taken from the fungal culture was distributed to four corners of the PDA medium prepared on the slide that was then sealed by a glass coverslip and placed on a sterile wet filter paper in a petri dish to maintain the humidity. After 14 days, the appressoria, which developed under the coverslips, were collected and placed on a glass slide for observation under a light microscope $^{1}$. The identification of putative Colletotrichum strains was based on the description of Than et al. $(2008)^{17}$.

\section{Identification of pathogenic fungi species via sequencing}

Based on the morphological characterization, the putative Colletotrichum samples grown on PDA medium were sent to the PHUSA Biochem LTD. company for sequencing, using the ITS1 primer (CTTGGTCATTTAGAGGAAGTAA). The sequenced ITS regions were used for the sequence homology analysis. To identify Colletotrichum species, the sequencing results of the putative Colletotrichum samples were used to BLAST with sequences available from GenBank Nucleotide database of NCBI (National Center for Biotechnology Information).

\section{Pathogenicity test}

The two isolated Colletotrichum strains were used to study the anthracnose resistance of eleven chili pepper cultivars. Colletotrichum isolates were incubated on PDA medium at $25^{\circ} \mathrm{C}$ for 14 days. To collect the fungal conidia, $5 \mathrm{ml}$ of sterile water was added directly on the culture surface, followed by gently shaking of the petri dish. The conidia suspensions were collected to $1.5-\mathrm{ml}$ tubes and centrifuged at $10000 \mathrm{rpm}$. The pellets that contained the concentrated conidia, was adjusted with sterile water to $10^{5}$ conidia per ml using a hemocytometer.

For the pathogenicity test, the experiment was performed twice to confirm the phenotype. In each replicate, two to six fully developed green fruits from each cultivar were injected with $10 \mu \mathrm{l}$ of the conidia suspensions $\left(10^{5}\right.$ conidia per $\left.\mathrm{ml}\right)$. Sterile waterinfiltrated fruits were used as control. Three technical replicates were performed by injecting on three different places of a fruit of the cultivar that had medium or large fruits. To develop the disease, inoculated fruits were secured in plastic containers lined with wet paper towels and incubated for seven days at $25^{\circ} \mathrm{C}$. The 
development of disease symptoms was observed, and the lesion diameter was measured every $24 \mathrm{~h}$. The lesion diameter was determined by averaging the largest and the smallest diameters of each lesion. The mean of lesion diameters at seven days after injection were used to determine the resistance of eleven chili pepper cultivars to the particular fungal isolate. Data of lesion diameter from two replicates were statistically analyzed using analysis of variance $(\mathrm{P}<0.05)$, followed by multiple range tests using Tukey's HSD test with SPSS 16.0 software (IBM).

\section{Plant DNA extraction and PCR amplification}

The genomic DNA of chili pepper was extracted using the CTAB method ${ }^{18}$. The DNA quality and purity were determined by nanodrop (ND-2000, Thermo Scientific). To verify the presence of anthracnose resistance-associated markers in different chili pepper cultivars, polymerase chain reactions (PCRs) were performed using primers listed in Table 1. PCRs using Taq DNA polymerase and other components were prepared according to the manufacturer's instruction (BIO-21105, Bioline). The thermal cycle was started with a denaturation step at $95^{\circ} \mathrm{C}$ for $5 \mathrm{~min}$, followed by 35 cycles of $95^{\circ} \mathrm{C} 30 \mathrm{~s}, 60^{\circ} \mathrm{C} 30 \mathrm{~s}, 72^{\circ} \mathrm{C} 1 \mathrm{~min}$, and ended by a 2 -min extension step at $72{ }^{\circ} \mathrm{C}$. Reactions were held at $4{ }^{\circ} \mathrm{C}$. Depending on the product size, 2 to $4 \%$ agarose gel was used to migrate DNA under 150 $\mathrm{V}$ constant voltage for $50 \mathrm{~min}$. DNA was then visualized under UV light, and DNA size was determined according to the 100-bp ladder (SM0241, Thermo Scientific).

\section{RESULTS}

\section{Isolates obtained from infected fruits}

From the infected fruits collected from chili pepper fields in Tra Vinh province, five different fungal isolates were obtained. Among these isolates, two putative Colletotrichum strains, named $18 \mathrm{~T}$ and $21 \mathrm{~T}$, were identified. The morphology analysis was performed according to the morphological descriptions of Colletotrichum species outlined by Than et al. (2008) ${ }^{17}$. Colonies of the $18 \mathrm{~T}$ strain grown on PDA showed pale orange color with fluffy aerial mycelia on the colony surface (Figure $1 \mathrm{~A}$ ). Conidia of the $18 \mathrm{~T}$ isolate were smooth-walled, transparent, colorless straight, cylindrical form with uneven ends. The size of the conidia was $10-14-\mu \mathrm{m}$ long and $3-4-\mu \mathrm{m}$ wide. The $18 \mathrm{~T}$ appressoria were ovoid to ellipsoidal, $6-9-\mu \mathrm{m}$ long, 4 $-6-\mu \mathrm{m}$ wide, with medium to dark brown color. On the other hand, the colonies of the $21 \mathrm{~T}$ strain grown on PDA were grey to pale orange with thin cottony mycelia on the surface (Figure $1 \mathrm{~B}$ ). The $21 \mathrm{~T}$ isolate produced fusiform conidia with both acute ends, 7 $13-\mu \mathrm{m}$ long and 3-4- $\mu \mathrm{m}$ wide. Most of the $21 \mathrm{~T}$ appressoria were irregularly shaped, $5-8-\mu \mathrm{m}$ long, $3-$ 4- $\mu \mathrm{m}$ wide.

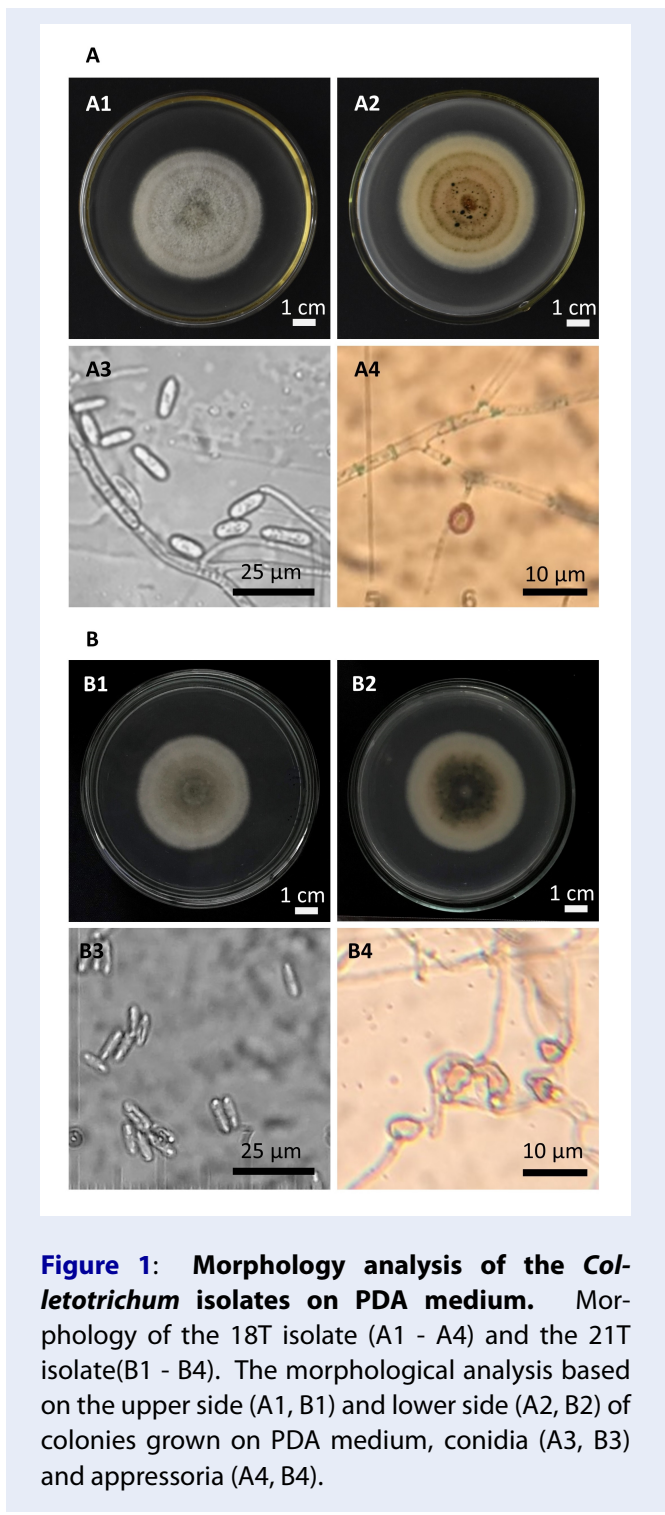

The species of the two putative Colletotrichum isolates were identified by sequencing the ITS region using the ITS1 primer. The sequencing result successfully confirmed the prediction that was based on the morphology observation. By comparing with the Colletotrichum sequence database from NCBI, the ITS sequences of the $18 \mathrm{~T}$ and $21 \mathrm{~T}$ isolates showed the highest similarity to Colletotrichum scovillei (Accession number: MH603141.1) and C. acutatum (Accession number: MF629920.1), respectively (data not 
Table 1: List of molecular markers and the respective primers used in this study

\begin{tabular}{|c|c|c|c|}
\hline Marker name & Primer sequence ( 5 ' to $3^{\prime}$ ) & $\begin{array}{l}\text { Product } \\
\text { size }\end{array}$ & Reference \\
\hline \multirow[t]{2}{*}{ HpmsE032 } & ATGCGCAAAGGGAGAAAATTCA & $282 \mathrm{bp}$ & Suwor et al. (2017) \\
\hline & CGAACTAACCGTTCATGGTGGA & & \\
\hline \multirow[t]{2}{*}{ HpmsE116 } & ТСТСТСТСТАСАТСТСТCCGTTGA & $245 \mathrm{bp}$ & Yi et al. (2006) \\
\hline & ACTCCCATACGGTGTCGTTC & & Sun et al. (2015) \\
\hline \multirow[t]{2}{*}{ HpmsE126 } & TGGGTATTTCCTTGCTGGAG & $108 \mathrm{bp}$ & \\
\hline & TCCTTCCAGGAAACTGATGG & & \\
\hline \multirow[t]{2}{*}{ HpmsE047 } & AACCCGTGTTCAATCCCCAAAT & $252 \mathrm{bp}$ & Jayaram et al. (2015) \\
\hline & TGGCCATACCACCAGCAGTAGA & & \\
\hline
\end{tabular}

shown). Therefore, together with the morphology observation, the $18 \mathrm{~T}$ and $21 \mathrm{~T}$ isolates were identified as C. scovillei and C. acutatum, respectively. These two fungal strains were later used in the experiment to determine the anthracnose resistance of different chili pepper cultivars.

\section{Pathogenicity testing}

Fruits from 11 chili pepper cultivars were infected with the two isolates of Colletotrichum species, $C$. scovillei and C. acutatum. Both isolates were pathogenic and could successfully infect most of the cultivars. The infected areas were all rounded-shape with concentric acervuli (Figure $2 \mathrm{~A}$ ). The lesion diameters of the eleven cultivars injected with the two Colletotrichum isolates were described in table 2. The water-injected fruits significantly showed no lesion in eleven cultivars at seven days after injection (Figure 2). When injected with the Colletotrichum conidia, the lesion diameters were all significantly larger than their corresponding water-injected controls (Figure $2 \mathrm{~B}$ ). There were also significant differences in lesion diameter among eleven cultivars. The two cultivars, including CN404 and HNCS showed the strongest resistance to both Colletotrichum species with the smallest infection diameter, smaller than 3 $\mathrm{mm}$. In these cultivars, larger lesion diameters when infected by C. acutatum compared to that infected by C. scovillei indicated that they were more resistant to C. scovillei. Additionally, TN535 and HNNS were the two most susceptible cultivars to both Colletotrichum species due to their large lesion diameters when infected by these two pathogens. The resistance level to C. scovillei was similar to C. acutatum in each cultivar, with the exception of the TV3 and PN400 cultivars (Figure $2 \mathrm{~B}$ ). TV3 was strongly resistant to $C$. scovillei ( $3 \mathrm{~mm}$ in lesion diameter), but moderately resistance to C. acutatum (6 $\mathrm{mm}$ in lesion diameter). The PN400 cultivar, on the other hand, was susceptible to the C. scovillei ( $11.5 \mathrm{~mm}$ in lesion diameter) but showed the moderate resistance to C. acutatum (7.5 $\mathrm{mm}$ in lesion diameter).

\section{Potential anthracnose resistance- associated molecular markers}

Four different PCR-based molecular markers (SSR markers), were tested to determine the potential molecular marker related to the anthracnose resistance in Vietnamese chili pepper cultivars. PCRs were performed for eleven chili pepper cultivars, and the summary of results was presented in table 2. Among the four tested molecular markers, HpmsE032, HpmsE047, and HpmsE116 were detected in both resistant and susceptible cultivars indicating these markers are not associated with the anthracnose resistance caused by defined Colletotrichum species (Figure 3 B-D). Interestingly, the HpmsE126 marker was observed only in two of three anthracnose resistant cultivars, CN404 and TV3 (Figure 3 A). These two chili pepper cultivars carrying HpmsE126 showed very strong resistance to anthracnose since their lesion diameter was significantly lower than the lesion diameter in the cultivars without this marker. The data analysis also suggested that having HpmsE126 marker might contribute more to C. scovillei resistance than C. acutatum resistance (Figure 4). Among the markers showing differences between cultivars, HpmsE126 was observed in the two cultivars, CN404 and TV3, which had a very strong resistance to anthracnose, especially the disease caused by $C$. scovillei. As a result, the HpmsE126 might be related to the resistance to anthracnose and would be a potential molecular marker used in chili pepper breeding. Given that these chili pepper cultivars showed 
A

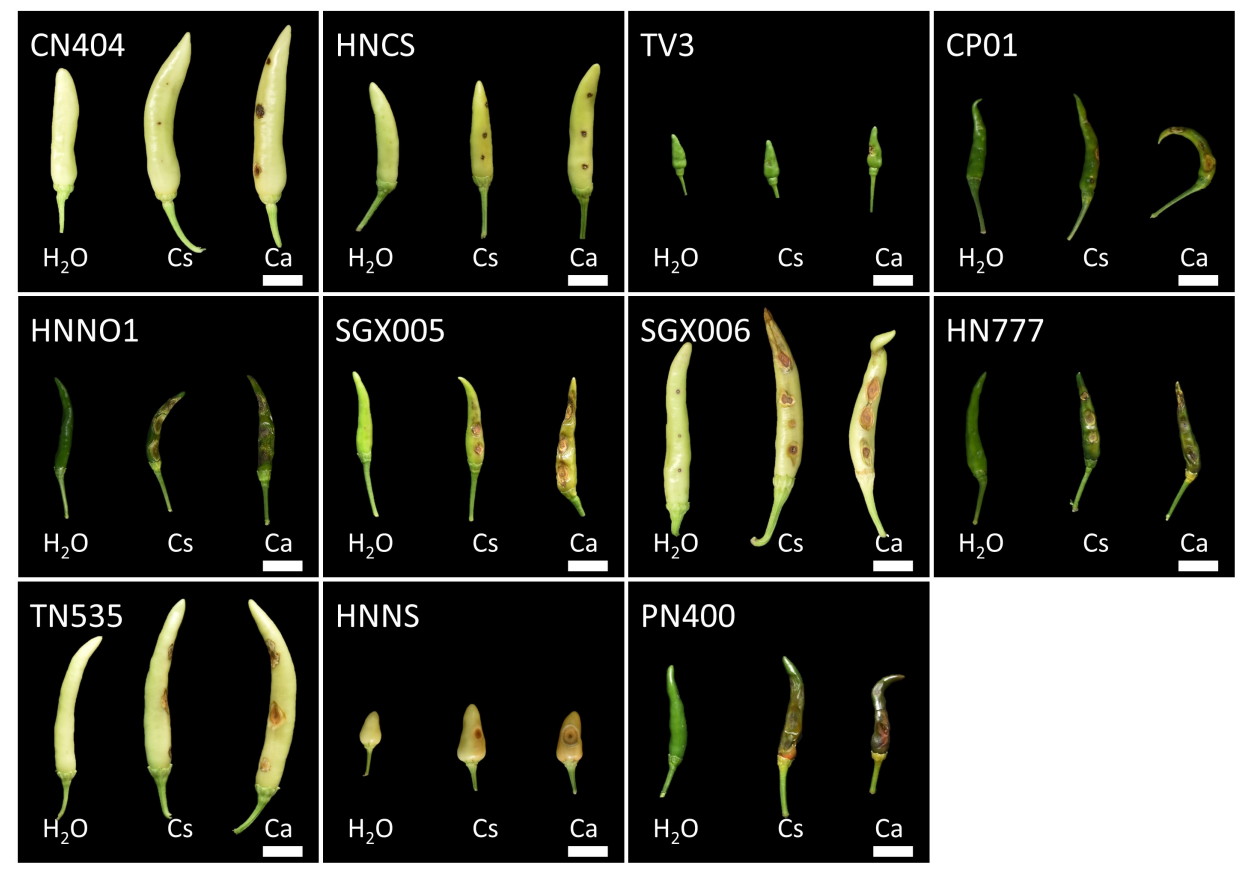

B

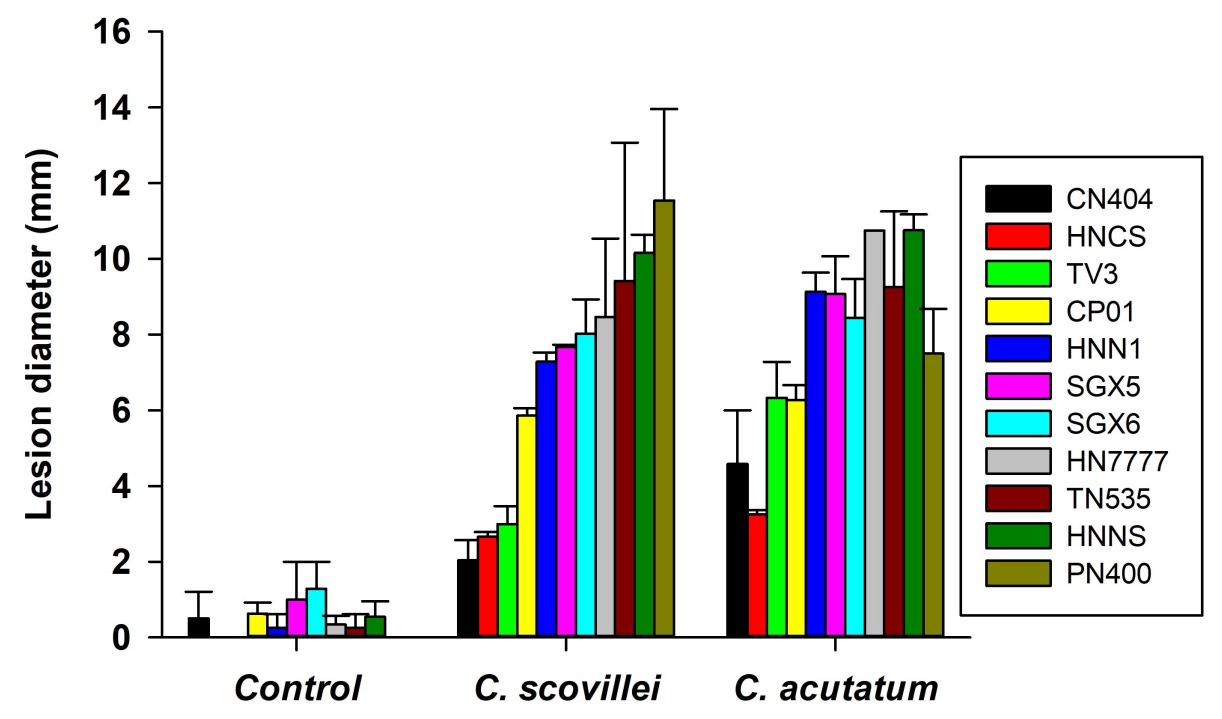

Figure 2: Anthracnose symptoms on chili fruits from different cultivars at 7 days after injection. (A) Disease symptoms developed on chili fruits from eleven cultivars after injection with either $C$. scovillei (Cs) or C. acutatum (Ca) isolates. The water-injected fruits were used as control $(\mathrm{H} 2 \mathrm{O})$. Scale bars represent $1 \mathrm{~cm}$. (B) Comparison of lesion diameter caused by the two Colletotrichum isolates on eleven chili pepper cultivars. Mean represents data from two independent replicates. Error bars represent the standard deviation. 
Table 2: Lesion diameter caused by two Colletotrichum isolates in each cultivar and the detected molecular markers

\begin{tabular}{|c|c|c|c|c|c|c|}
\hline \multirow[t]{2}{*}{ Cultivar } & \multicolumn{2}{|c|}{ Lesion diameter } & HpmsE126 & HpmsE032 & HpmsE047 & HpmsE116 \\
\hline & C. scovillei & C. acutatum & & & & \\
\hline CN404 & $2.04 \mathrm{a}$ & $4.58 \mathrm{ab}$ & $\mathrm{X}$ & $\mathrm{X}$ & $\mathrm{X}$ & $\mathrm{X}$ \\
\hline HNCS & $2.67 \mathrm{ab}$ & $3.25 \mathrm{a}$ & & $\mathrm{X}$ & $\mathrm{X}$ & $\mathrm{X}$ \\
\hline TV3 & $3.00 \mathrm{ab}$ & $6.33 \mathrm{abc}$ & $\mathrm{X}$ & $\mathrm{X}$ & $\mathrm{X}$ & $\mathrm{X}$ \\
\hline СР01 & $5.86 \mathrm{abc}$ & $6.28 \mathrm{abc}$ & & $\mathrm{X}$ & $\mathrm{X}$ & $\mathrm{X}$ \\
\hline HNNo1 & $7.28 \mathrm{abc}$ & $9.13 \mathrm{~cd}$ & & $\mathrm{X}$ & $\mathrm{X}$ & $\mathrm{X}$ \\
\hline SGX005 & $7.66 \mathrm{abc}$ & $9.08 \mathrm{~cd}$ & & $\mathrm{X}$ & $\mathrm{X}$ & $\mathrm{X}$ \\
\hline SGX006 & $8.02 b c$ & $8.44 \mathrm{bcd}$ & & $\mathrm{X}$ & $\mathrm{X}$ & $\mathrm{X}$ \\
\hline HN7777 & $8.47 \mathrm{c}$ & $10.75 \mathrm{~d}$ & & $\mathrm{X}$ & $\mathrm{X}$ & $\mathrm{X}$ \\
\hline TN535 & $9.42 \mathrm{c}$ & $9.25 \mathrm{~cd}$ & & $\mathrm{X}$ & $\mathrm{X}$ & $\mathrm{X}$ \\
\hline HNNS & $10.16 \mathrm{c}$ & $10.75 \mathrm{~d}$ & & $\mathrm{X}$ & $\mathrm{X}$ & $\mathrm{X}$ \\
\hline PN400 & $11.54 \mathrm{c}$ & $7.50 \mathrm{bcd}$ & & $\mathrm{X}$ & $\mathrm{X}$ & $\mathrm{X}$ \\
\hline
\end{tabular}

${ }^{*}$ Different letters indicate statistically significant difference (ANOVA, Tukey’s HSD test, $\mathrm{P}<0.05$ )

stronger resistance to C. scovillei compared to C. acutatum, the HpmsE126 marker might be more related to the C. scovillei resistance in chili pepper. Interestingly, it must be noticed that the HNCS cultivar was among the best anthracnose resistant cultivars in this study, although the HpmsE126 marker was not found in this cultivar (Figure $3 \mathrm{~A}$ ).

\section{DISCUSSION}

In addition to C. acutatum isolation, which was previously identified in studies in Vietnam ${ }^{7,8}$, different Colletotrichum species causing anthracnose disease in chili pepper in Vietnam, C. scovillei, was firstly identified in this study. This Colletotrichum species was previously reported to cause chili anthracnose disease in Japan, Brazil, China, and Korea ${ }^{6,19-21}$. Recently, it was shown that in South Asia and South-East Asia, except Sri Lanka, C. scovillei was the prevalent anthracnose-causing pathogen and showed very high aggressiveness when infecting non-wounded fruits ${ }^{22}$. In the study of Oo et al. (2017), all 36 tested cultivars belonging to C. annuum, C. chacoense, and C. baccatum, were susceptible to the $C$. scovillei isolates ${ }^{6}$. Crossing between C. annuum and C. baccatum conferred to the resistance to $C$. scovillei in hybrid sweet pepper was reported in $2012^{6}$. Interestingly, among the tested cultivars in this study, three cultivars, including CN404, HNCS, and TV3, showed strong resistance to the C. scovillei isolate obtained from Tra Vinh province. These cultivars could be a valuable C. scovillei resistance source for chili pepper breeding.
According to the findings in this study, it is likely that the C. scovillei resistance trait has already been introduced into commercial chili pepper cultivars in Vietnam.

Most of the present commercial chili pepper cultivars belong to the C. annuum species. While C. annuum is commercially important, this species is highly anthracnose susceptible ${ }^{23}$. From the 1990s, the potential anthracnose resistance sources were identified in other chili pepper species, including C. baccatum (PBC80, PBC81) and C. chinense (PBC932) ${ }^{9}$. In 2014 , by studying the backcross $\mathrm{BC}_{1}$ population derived from the hybrid between $C$. annuum line 77013 and the C. chinense PBC932 using QTL analysis method, different markers, including HpmsE116 and HpmsE126, were identified to be closely related to the resistance of chili pepper fruit to C. acutatum $^{24,25}$. In this current study, only the HpmsE126 was found to be related to moderate anthracnose resistance caused by $C$. acutatum. Interestingly, plants carrying this marker also showed additional strong resistance to C. scovillei, suggesting that a common mechanism might be shared between $C$. acutatum resistance and C. scovillei resistance. Although HpmsE126 was considered as a minor QTL related to anthracnose resistance, in the current study, this marker was more efficient in identifying the anthracnose-resistant cultivars compared to the other markers. Other markers, HpmsE032 and HpmsE047, were proven to be closely related to the anthracnose resistance ${ }^{26,27}$. However, 


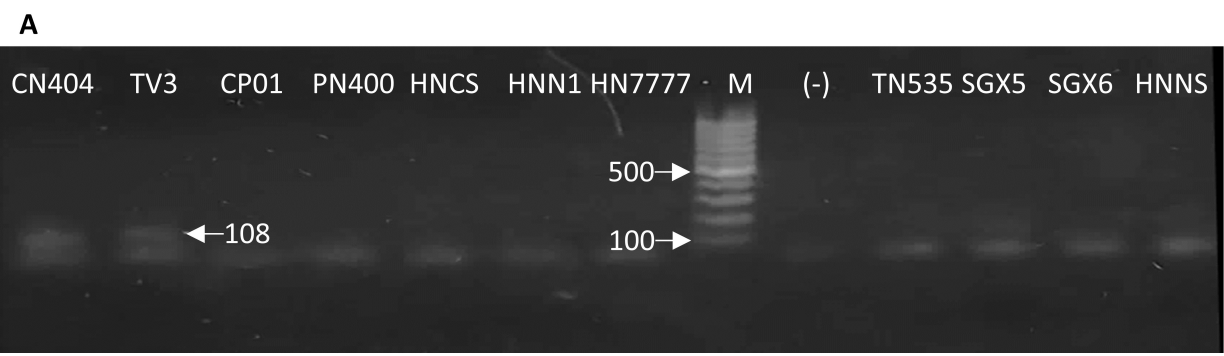

B

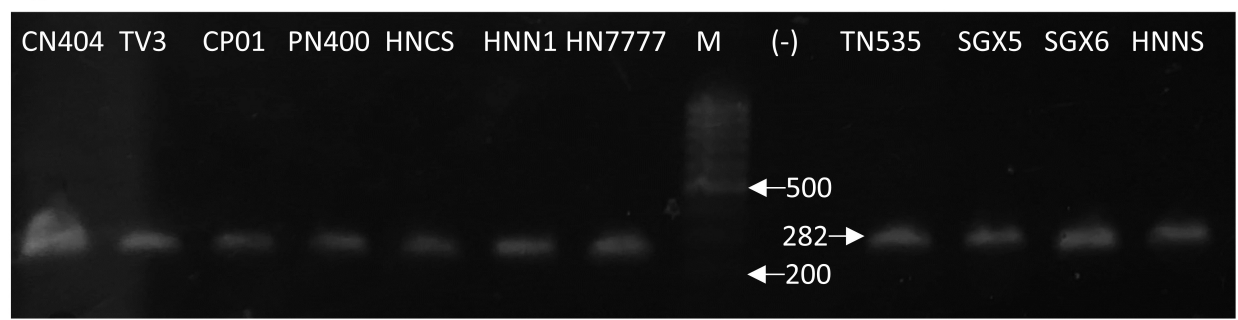

C

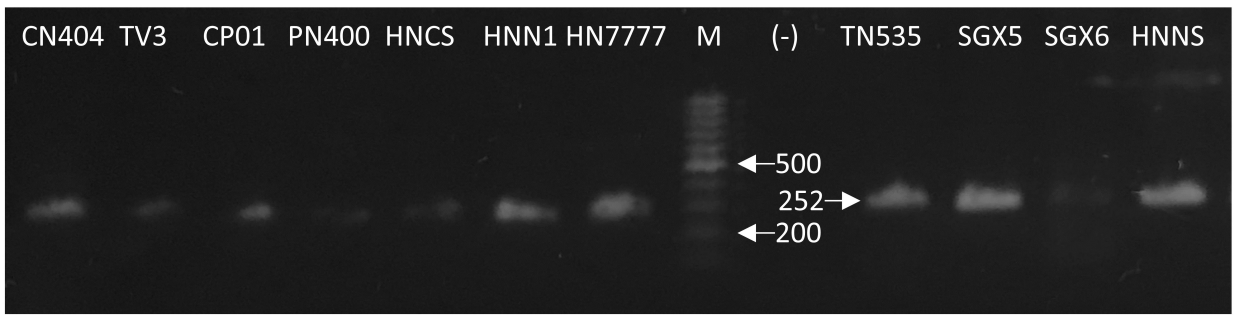

D

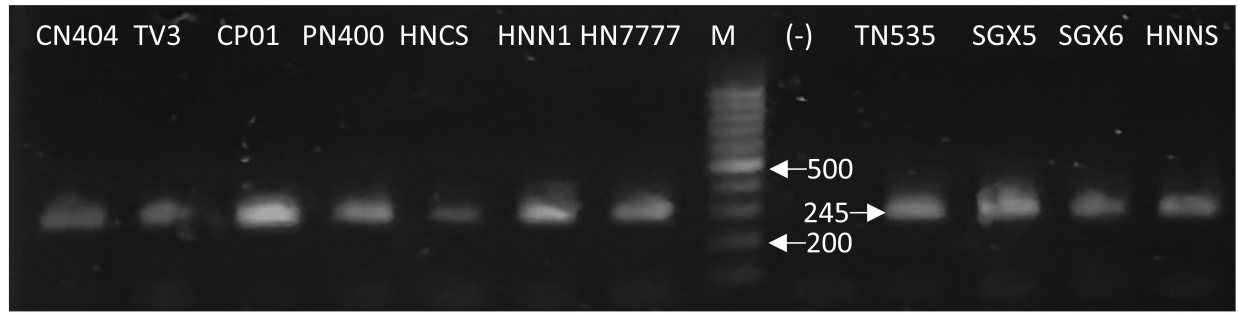

Figure 3: DNA electrophoresis of molecular markers amplified by PCRs in different chili pepper cultivars. Marker detection of HpmsE126 (A), HpmsE032 (B), HpmsE047 (C) and HpmsE116 (D) in eleven chili pepper cultivars. Lane M: 100-bp DNA Ladder, lane (-): DEPC-treated H2O. All PCR products were migrated in $2 \%$ agarose gel.

in this study, these markers were not able to determine the anthracnose resistance variance in the tested chili pepper cultivars. It must be noted that the anthracnose disease in chili pepper is caused by different Colletotrichum species. HpmsE047 was determined as a disease resistance marker when tested with $C$. gloeosporioides and C. capsici ${ }^{26,28}$. It is possible that chili pepper employs different molecular mechanisms to fight against different Colletotrichum species. In the case of HpmsE032, although this marker was proven to be a C. acutatum-resistant marker, its efficiency was only $65 \%$ suggesting the involvement of other genes yet unidentified in the defence mechanism against $C$. acutatum and the combination of different marker would be more efficient in the detection of resistant cultivar ${ }^{27}$. In 2011, Lee et al. identified two markers related to the resistance to C. scovillei/C. acutatum (CaR12.2) and C. truncatum/C. capsici (CcR9). The later marker was developed to SCAR marker (CCR9M1-SCAR) and was protected under the worldwide patent KR101010446B1 ${ }^{13,28}$. These markers could be the potential additional tools for the detection of anthracnose-resistant cultivars, although its application in Vietnam could be difficult 


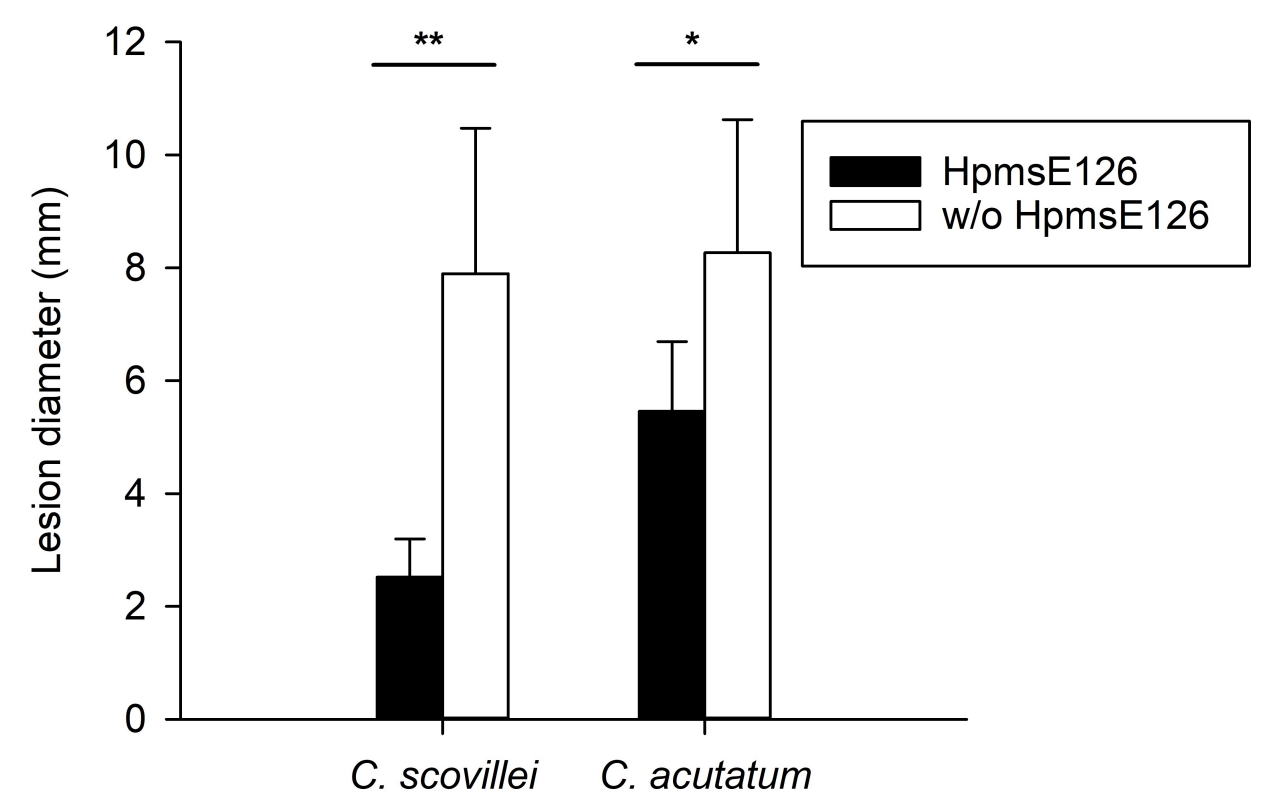

Figure 4: Comparison of lesion diameter between cultivars having HpmsE1 26 marker and cultivars without HpmsE126 marker. Data is presented as mean \pm SD. Means were compared using Student's t-test. Statistical difference is presented by either $\left({ }^{*}\right)(P<0.05)$ or $\left.{ }^{* *}\right)(P<0.01)$.

due to patent protection. In this current study, the strong resistance to both C. scovillei and C. acutatum of the HNCS cultivar without HpmsE126 marker supported the involvement of other gene clusters and other mechanisms in the resistance to C. scovillei and C. acutatum and the possibility to combine with other molecular markers in the determination of anthracnose resistance caused by C. scovillei and C. acutatum in chili pepper. The findings also support that the CN404 cultivar could be a very good commercial chili pepper cultivar for chili production and cultivation, especially in the regions affected by $C$. scovillei and C. acutatum. Additionally, the wild bird-eye chili pepper cultivar found in Tra Vinh province could be a potential anthracnose resistance source, which can be applied for chili pepper breeding.

\section{CONCLUSION}

In this study, from the infected fruits collected from chili pepper fields in Tra Vinh province, two Colletotrichum isolates, C. scovillei and C. acutatum, were successfully isolated and identified using morphological and sequencing approaches. Among eleven tested chili pepper cultivars infected by these Colletotrichum isolates, two cultivars were identified to have the resistance against both of these pathogens. Moreover, the marker analysis found the HpmsE126 SSR marker in the two C. scovillei resistant cultivars. The HpmsE126 might be an efficient molecular tool to identify the anthracnose-resistant cultivars for chili pepper breeding.

\section{ABBREVIATIONS}

ITS Internal transcribed spacer

SSR Simple Sequence Repeats

SCAR Sequence Characterized Amplified Region

NCBI National Center for Biotechnology Information

\section{COMPETING INTERESTS}

The authors declare that they have no competing interests.

\section{AUTHOR CONTRIBUTIONS}

All the experimental works were performed by VA Ly. TPT Truong was involved in the pathogen isolation and molecular biology works. The project design and manuscript writing were performed by TH Nguyen.

\section{ACKNOWLEDGEMENT}

This research is funded by University of Science, VNU-HCM, under grant number T2018-17 


\section{REFERENCES}

1. Oo MM, Yoon HY, Jang HA, Oh SK. Identification and characterization of Colletotrichum species associated with bitter rot disease of apple in South Korea. The plant pathology journal. 2018;34(6):480.

2. Nelson SC. Mango anthracnose (Colletotrichum gloeosporiodes). Plant Dis 48 College of Tropical Agriculture and Human Resources (CTAHR), University of Hawai at Mänoa, Honolulu, Hawai. 2008;Available from: www.ctahr.hawaii.edu/oc/ freepubs/pdf/pd-48.pdf.

3. Nguyen PTH, Pettersson OV, Olsson P, Liljeroth E. Identification of Colletotrichum species associated with anthracnose disease of coffee in Vietnam. European Journal of Plant Pathology. 2010;127(1):73-87. Available from: https://doi.org/ 10.1007/s10658-009-9573-5.

4. Kim HJ, Lee EJ, Park SH, Lee HS, Chung N. Biological control of anthracnose (Colletotrichum gloeosporioides) in pepper and cherry tomato by Streptomyces sp. A1022. Journal of Agricultural Science. 2014;6(2):54. Available from: https: //doi.org/10.5539/jas.v6n2p54.

5. Than PP, Prihastuti H, Phoulivong S, Taylor PW, Hyde KD. Chilli anthracnose disease caused by Colletotrichum species. Journal of Zhejiang University Science B. 2008;9(10):764. PMID: 18837103. Available from: https://doi.org/10.1631/jzus. B0860007.

6. Oo MM, Lim G, Jang HA, Oh SK. Characterization and pathogenicity of new record of anthracnose on various chili varieties caused by Colletotrichum scovillei in Korea. Mycobiology. 2017;45(3):184-191. PMID: 29138623. Available from: https://doi.org/10.5941/MYCO.2017.45.3.184.

7. Don L, Van T, Phuong VT, Kieu P. Colletotrichum spp. Attacking on Chilli Pepper Growing in Vietnam. Country Report Abstracts of the First International Symposium on Chilli Anthracnose National Horticultural Research Institute, Rural Development of Administration, Republic of Korea. 2007.

8. Hung ND, Cuong HV, Lam HC. Detection of Colletotrichum Species Causing Anthracnose of Chili by Polymerase Chain reaction. Vietnam J Agri Sc. 2018;16(12):1025-1038.

9. Gniffke $P$, Shieh $S$, et al. Pepper research and breeding at AVRDC-The World Vegetable Center. XV EUCARPIA Meeting on Genetics and Breeding of Capsicum and Eggplant (2-4 September)'. Turin, Italy: Citeseer. 2013;

10. Kim SH, Yoon JB, Do JW, Park HG. Resistance to anthracnose caused by Colletotrichum acutatum in chili pepper (Capsicum annuum L.). J Crop Sci Biotech. 2007;10(4):277-280.

11. Voorrips RE, Finkers R, Sanjaya L, Groenwold R. QTL mapping of anthracnose (Colletotrichum spp.) resistance in a cross between Capsicum annuum and C. chinense. Theoretical and Applied Genetics. 2004;109(6):1275-1282. PMID: 15309301. Available from: https://doi.org/10.1007/s00122-004-1738-1.

12. Lee J, Hong JH, Do JW, Yoon JB. Identification of QTLs for resistance to anthracnose to two Colletotrichum species in pepper. Journal of Crop Science and Biotechnology. 2010;13(4):227-233. Available from: https://doi.org/10.1007/ s12892-010-0081-0.

13. Lee J, Do JW, Yoon JB. Development of STS markers linked to the major QTLs for resistance to the pepper anthracnose caused by Colletotrichum acutatum and C. capsici. Horticulture, Environment, and Biotechnology. 2011;52(6):596-601. Available from: https://doi.org/10.1007/s13580-011-0178-5.

14. Suwor $P$, Thummabenjapone $P$, Sanitchon J, Kumar $S$, Techawongstien $\mathrm{S}$. Phenotypic and genotypic responses of chili (Capsicum annuum L.) progressive lines with different resistant genes against anthracnose pathogen (Colletotrichum spp.). European journal of plant pathology. 2015;143(4):725736. Available from: https://doi.org/10.1007/s10658-0150723-7.
15. Wang Y. Development of Sequence characterized amplified region (SCAR) markers associated with pepper anthracnose (Colletotrichum acutatum) resistance. National Chiayi University. 2011;

16. Ridzuan R, Rafii MY, Ismail SI, Mohammad YM, Miah G, Usman M. Breeding for anthracnose disease resistance in chili: progress and prospects. International journal of molecular sciences. 2018;19(10):3122. PMID: 30314374. Available from: https://doi.org/10.3390/ijms19103122.

17. Than $P$, Jeewon $R$, Hyde $K$, Pongsupasamit $S$, Mongkolporn O, Taylor P. Characterization and pathogenicity of Colletotrichum species associated with anthracnose on chilli (Capsicum spp.) in Thailand. Plant Pathology. 2008;57(3):562572. Available from: https://doi.org/10.1111/j.1365-3059.2007. 01782.x.

18. Doyle JJ. Isolation of plant DNA from fresh tissue. Focus. 1990;12:13-15.

19. Kanto T, Uematsu S, Tsukamoto T, Moriwaki J, Yamagishi N, Usami T, et al. Anthracnose of sweet pepper caused by Colletotrichum scovillei in Japan. Journal of general plant pathology. 2014;80(1):73-78. Available from: https://doi.org/ 10.1007/s10327-013-0496-9.

20. Caires N, Pinho D, Souza J, Silva M, Lisboa D, Pereira O, et al. First report of anthracnose on pepper fruit caused by Colletotrichum scovillei in Brazil. Plant disease. 2014;98(10):1437. PMID: 30703977. Available from: https://doi.org/10.1094/ PDIS-04-14-0426-PDN.

21. Zhao W, Wang T, Chen Q, Chi Y, Swe T, Qi R. First report of Colletotrichum scovillei causing anthracnose fruit rot on pepper in Anhui Province, China. Plant Disease. 2016;100(10):2168. Available from: https://doi.org/10.1094/ PDIS-04-16-0443-PDN.

22. Silva DD, Groenewald JZ, Crous PW, Ades PK, Nasruddin A, Mongkolporn $\mathrm{O}$, et al. Identification, prevalence and pathogenicity of Colletotrichum species causing anthracnose of Capsicum annuum in Asia. IMA Fungus. 2019;10(1):1. PMID: 32355609. Available from: https://doi.org/10.1186/s43008019-0001-y

23. Ramchiary N, Kole C. The Capsicum Genome. Springer. 2019;Available from: https://doi.org/10.1007/978-3-31997217-6.

24. Sun C, Mao SL, Zhang ZH, Palloix A, Wang LH, Zhang BX. Resistances to anthracnose (Colletotrichum acutatum) of Capsicum mature green and ripe fruit are controlled by a major dominant cluster of QTLs on chromosome P5. Scientia Horticulturae. 2015;181:81-88. Available from: https://doi.org/10. 1016/j.scienta.2014.10.033.

25. YiG, Lee JM, Lee S, Choi D, Kim BD. Exploitation of pepper ESTSSRs and an SSR-based linkage map. Theoretical and Applied Genetics. 2006;114(1):113-130. PMID: 17047912. Available from: https://doi.org/10.1007/s00122-006-0415-y.

26. Jayaram N, Rao AM, Ramesh S, Manjunath B, Mangalagowri N, Ashwini M. Tagging SSR Markers to Genotic Regions Associated with Anthracnose Disease Resistance and Productivity per seTraits in Hot Pepper (Capsicum annuum L.). Environment \& Ecology. 2016;34(4A):1440-1446.

27. Suwor $P$, Sanitchon J, Thummabenjapone P, Techawongstien $\mathrm{S}$, Kumar $\mathrm{S}$. Inheritance analysis of anthracnose resistance and marker-assisted selection in introgression populations of chili (Capsicum annuum L.). Scientia Horticulturae. 2017;220:2026. Available from: https://doi.org/10.1016/j.scienta.2017.03. 032.

28. Barka GD, Lee J. Molecular Marker Development and Gene Cloning for Diverse Disease Resistance in Pepper (Capsicum annuum L.): Current Status and Prospects. Plant Breeding and Biotechnology. 2020;8(2):89-113. Available from: https://doi. org/10.9787/PBB.2020.8.2.89. 